\title{
Surface Engineering of Polymer Sheet by Plasma Techniques and Atom Transfer Radical Polymerization for Covalent Immobilization of Biomolecules
}

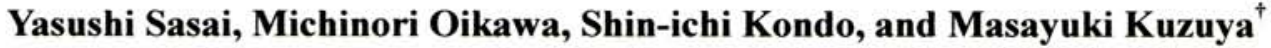 \\ Laboratory of Pharmaceutical Physical Chemistry, Gifu Pharmaceutical University, \\ 5-6-1 Mitahora-Higashi, Gifu 502-8585, Japan \\ ${ }^{\dagger}$ Department of Pharmaceutical Physical Chemistry, Faculty of Pharmaceutical Science, \\ Matsuyama University, 4-2 Bunkyo-cho, Matsuyama, Ehime 790-8578 Japan \\ sasai@gifu-pu.ac.jp
}

\begin{abstract}
Keywords: plasma irradiation, atom transfer radical polymerization, polyethylene, glycidyl methacrylate, urokinase
\end{abstract}

\section{Introduction}

The covalent immobilization of biologically active macromolecules, such as deoxyribonucleic acid (DNA), enzyme and polysaccharides, onto polymer surfaces is great significance in many applications, especially in blood-compatible materials, biosensors and cell culture systems. For the successful development of such biomaterials, it is important to fabricate effective biointerfaces onto polymer substrates.

Cold plasmas have been used for an everincreasing number applications. This is related to the many advantages associated with the use of plasmas for surface modification of materials. One of the characteristics of plasma treatment is that it is surface-limited, so that only the surface properties can be changed without affecting the bulk properties. Thus, the plasma techniques have gained considerable interests in the development of advanced materials.

We have reported a novel method to introduce durable surface wettability and minimize its decay with time on several hydrophobic polymers (polyethylene-naphthalate copolymer, nylon-12 and low-density polyethylene (LDPE)) by plasma processing. [1-3] This method involves a sorption of vinylmethylether-maleic anhydride copolymer (VEMA), which is commercially known as a GANTREZ, into the surface layer and the immobilization by plasma-assisted cross-link reaction, followed by hydrolysis of VEMA to generate hydrophilic carboxylic acid groups (VEMAC) on the surface. The conceptual procedure is sequentially illustrated in Fig. 1.

We have previously reported on the fabrication of polyglycidylmethacrylate (pGMA) brushes as an interface on the VEMAC-immobilized LDPE (LDPE/VEMAC) sheet by well-defined process using atom transfer radical polymerization (ATRP) and succeeded in the immobilization of fibrinolytic

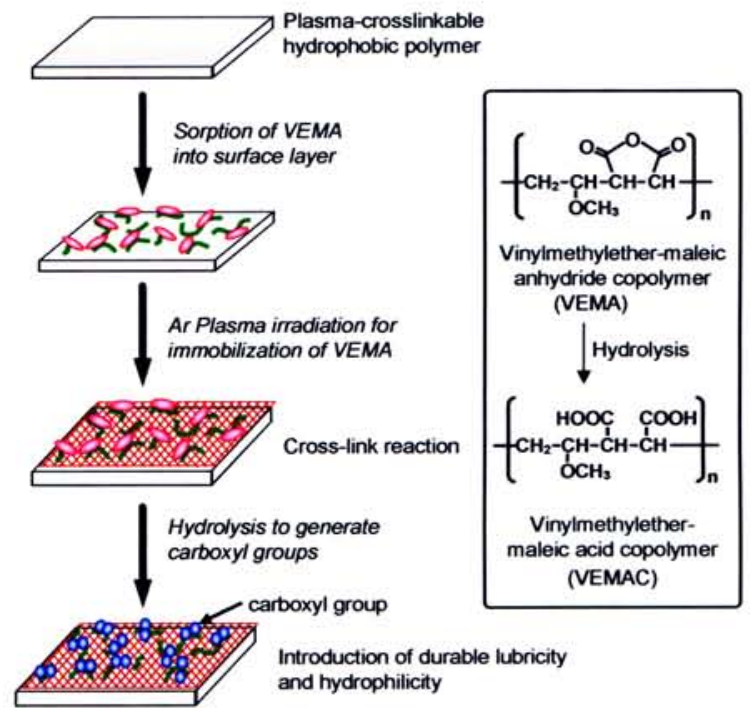

Fig. 1 Schematic illustration of fabrication of durable hydrophilicity on a polymer surface. 
enzyme, urokinase (UK), on the pGMA-grafted LDPE surfaces through the direct coupling with epoxide groups of GMA. [4] In this communication, we studied the effect of the interfaces prepared by various conditions on the enzymatic activity of UK immobilized on the LDPE surface.

\section{Experimental}

\subsection{Preparation of LDPE/VEMAC sheet}

A LDPE/VEMAC sheet was prepared according to the method reported previously.[1-3] LDPE sheet $(10 \mathrm{~mm} \times 30 \mathrm{~mm})$ was immersed in a $2 \%$ $(\mathrm{w} / \mathrm{v})$ solution of VEMA in a mixed solvent [cyclohexanone: $p$-xylene $(19: 1, \mathrm{v} / \mathrm{v})]$ for $6 \mathrm{~h}$ at $60^{\circ} \mathrm{C}$ to soak VEMA into LDPE surface layer, and the sample was dried in vcacuo overnight. Then, the sample sheet was soaked in tetrahydrofuran (THF) for $10 \mathrm{~s}$ to remove the excess VEMA. After drying, the sample sheet thus treated was submitted to Ar plasma irradiation to immobilize the VEMA onto LDPE surface layer. The plasma state was generated by the use of radio-frequency discharge of inductive coupling with five loop antenna at $13.56 \mathrm{MHz}$ with supplied power of $20 \mathrm{~W}$. Flow volume $(50 \mathrm{ml} / \mathrm{min})$ and pressure $(0.5$ Torr) of gas were controlled by changing evacuating speed. The sample sheet was placed on a glass-holder in a reaction chamber $(230 \mathrm{~mm}$ long, $45 \mathrm{~mm}$ in diameter) to ensure homogeneous exposure to plasma gas. After plasma irradiation for $30 \mathrm{~s}$, the hydrolysis of the maleic anhydride linkage in VEMA was conducted by immersing the VEMA- immobilized LDPE (LDPE/VEMA) sheet in $0.1 \mathrm{M}$ $\mathrm{NaOH}$ solution. The hydrolyzed LDPE/VEMA sheet was soaked in $1 \mathrm{M} \mathrm{HCl}$ at room temperature and washed with distilled water.

\subsection{Surface-initiated ATRP of GMA}

The GMA grafted layer on the LDPE/VEMAC sheet was fabricated according to the method reported previously. [4] Figure 2 shows the reaction scheme for ATRP of GMA from LDPE/ VEMAC surface. The LDPE/VEMAC sheet was placed into a $3 \%(\mathrm{w} / \mathrm{v})$ solution of $\mathrm{PCl}_{5}$ in methylene chloride at room temperature for $15 \mathrm{~min}$ to convert the surface carboxylic acid groups to acid chloride groups, and washed sequentially with methylene chloride and ethyl acetate. Then, the acid chloride-modified sheet was placed into a $4.5 \%(\mathrm{w} / \mathrm{v})$ solution of diethanolamine in a $4 \%$ $(\mathrm{w} / \mathrm{v}) \mathrm{KOH}$ aqueous solution at room temperature for $5 \mathrm{~h}$. After washing with distilled water, the hydroxyl-modified film thus prepared was put in a toluene solution containing 2-bromoisobutyryl bromide $(1.5 \mathrm{mM})$ and triethylamine $(1.5 \mathrm{mM})$ for $5 \mathrm{~h}$ at room temperature to immobilize the initiator for ATRP.

For the preparation of pGMA brushes on the LDPE surface, the reaction was carried out using a [GMA] $/[\mathrm{CuCl}] /\left[\mathrm{CuCl}_{2}\right] /\left[2,2^{\prime}\right.$ '-bipyridyl] feed ratio of 100:1:0.2:2 in $4 \mathrm{~mL}$ of a mixed solvent [DMF /water $(1: 1, \mathrm{v} / \mathrm{v})]$ under a nitrogen atmosphere in a glass ampule containing the initiator-immobilized LDPE/VEMAC sheet $(10 \mathrm{~mm} \times 10 \mathrm{~mm})$. The reaction was allowed to proceed for a prescribed

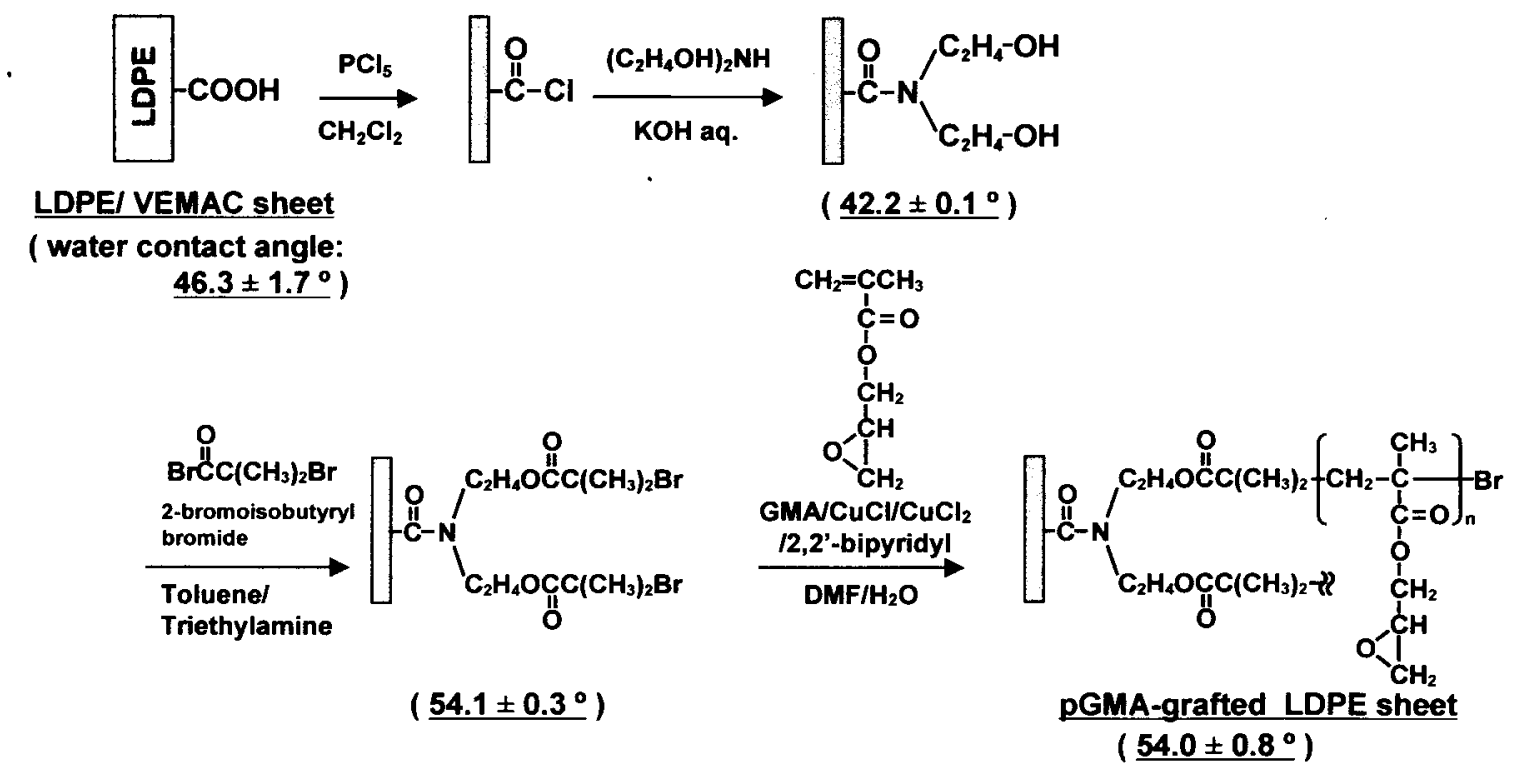

Fig. 2 Reaction scheme for fabrication of pGMA brushes on LDPE sheet by ATRP. 
period of time. The sample sheet was thoroughly washed with acetone to remove the adhered and physically adsorbed monomer and polymer.

2.3. Immobilization of $\mathrm{UK}$ on pGMA-grafted LDPE surface

Urokinase (UK) from human urine $(80,000$ $\mathrm{IU} / \mathrm{mg}$ ) was used as a model biomolecule for immobilization. The pGMA-grafted LDPE sheet $(10 \mathrm{~mm} \times 10 \mathrm{~mm})$ was transferred to $1 \mathrm{~mL}$ of 10 $\mathrm{mM}$ Tris- $\mathrm{HCl}$ buffer solution ( $\mathrm{pH} 9.0$ ) containing UK $(500 \mathrm{IU} / \mathrm{mL})$. Immobilization reaction was allowed to proceed at $4{ }^{\circ} \mathrm{C}$ for $48 \mathrm{~h}$ under shaking at $300 \mathrm{rpm}$. After the reaction, the UKimmobilized sheet was washed with $10 \mathrm{mM}$ phosphate buffer solution ( $\mathrm{pH} 7.0)$ to remove the physically adsorbed UK.

2.4. Immobilization of UK on LDPE/VEMAC sheet using coupling reagent

LDPE/VEMAC sheet was put into a aqueous solution containing $0.4 \mathrm{M} \mathrm{N}$-(3-dimethylaminopropyl)-N'-ethylcarbodiimide hydrochloride (EDC) and $0.1 \mathrm{M}$ N-hydorxysuccinimide (NHS) for $2 \mathrm{~h}$ to activate carboxyl groups on the sheet. After washing with distilled water, the sheet thus treated was transferred to $1 \mathrm{~mL}$ of $50 \mathrm{mM}$ borate buffer solution ( $\mathrm{pH} 9.0$ ) containing UK (500 IU/ $\mathrm{mL}$ ). The immobilization of UK on the sheet thus treated and washing after the immobilization reaction were conducted with the same procedure as mentioned above.

2.5. Determination of UK immobilized on the sheet

The amount of immobilized UK was determined by Bradford method using Bio-Rad protein dye reagent. The dye reagent concentrate was diluted five times with milliQ water. The diluted dye solution was added to a test tube containing UK-immobilized sheet and incubated at $25^{\circ} \mathrm{C}$ for 3 $\mathrm{h}$. Then the sheet was removed and the absorbance of the dye solution was measured at $465 \mathrm{~nm}$. The calibration curve for the determination of the amount of UK immobilized on the sheet was obtained using bovine gamma globulin solution.

2.6. Assay of enzyme activity of immobilized-UK on the sheet

Activity of immobilized-UK was assayed using its amidolytic effect on the peptide substrate, Glutaryl-Glycyl-L-Arginine-4-methyl-coumaryl-7 -amide (Glu-Gly-Arg-MCA). [5, 6] A Glu-GlyArg-MCA solution $(0.1 \mathrm{mM})$ in $10 \mathrm{mM}$ phosphate buffer solution $\left(\mathrm{pH} \mathrm{7.0)}\right.$ was preincubated at $37^{\circ} \mathrm{C}$ for $10 \mathrm{~min}$. The UK-immobilized sheet was added in the Glu-Gly-Arg-MCA solution and reacted at $37^{\circ} \mathrm{C}$ for $10 \mathrm{~min}$ under shaking at $300 \mathrm{rpm}$. The reaction was stopped by adding $20 \%(\mathrm{v} / \mathrm{v})$ acetic acid aqueous solution. The enzyme activity of immobilized-UK was determined by the measurement of fluorescence intensity of 7-amino4-methyl-coumarin liberated from the substrate with the excitation at $380 \mathrm{~nm}$ and emission at 460 $\mathrm{nm}$. The calibration curve for the determination was obtained by using soluble UK under the same condition.

\section{Results and Discussion}

We have previously reported the fabrication of well-controlled pGMA brushes on the LDPE surface by ATRP according to the method described in the experimental section. [4] The results indicated that the degree of polymerization increased linearly with the polymerization time. In this study, we examined the immobilization of UK on the pGMA-grafted surface prepared at various polymerization times, together with the directly immobilized UK on LDPE/VEMAC sheet using EDC/NHS system for the comparison purpose.

Table 1 shows the relative amount of immobilized UK against the standard protein and the enzyme activity determined using the peptide substrate. The relative activity shown in Table 1 means the percentage of active UK on the sheet, calculated from both values of the relative amount and the activity.

As can be seen from Table 1, the relative amount of immobilized UK increased with the polymerization time for the fabrication of pGMA brushes on the surface. The activity of immobilized UK also increased in the pGMA-grafted LDPE sheet prepared by ATRP up to $2 \mathrm{~h}$ but it then leveled off. Therefore, the relative activity of UK immobilized on pGMA-grafted LDPE sheet decreased with the increase in polymerization time. These results suggest that only the UK immobilized on the top surface of the pGMA grafted layer is active. On the other hand, the immobilized UK in the inside of grafted layer might be inactive due to the modification in the tertiary structure of UK and/or the diffusion disturbance of the peptide substrate.

In order to evaluate the stability of the immobilized UK, we examined the progressive changes of enzymatic activity of immobilized UK on pGMA-grafted LDPE and LDPE/VEMAC 
Table 1 The amount of immobilized UK and its activity on LDPE sheet

\begin{tabular}{lccc}
\hline Sample sheet & $\begin{array}{c}\text { Immobilized UK } \\
\left(\boldsymbol{\mu g} / \mathbf{c m}^{\mathbf{2}}\right)\end{array}$ & $\begin{array}{c}\text { Activity } \\
\left(\mathbf{I U} / \mathbf{c m}^{\mathbf{2}}\right)\end{array}$ & $\begin{array}{c}\text { Relative activity } \\
(\mathbf{\%})\end{array}$ \\
\hline GMA grafted LDPE (ATRP for $2 \mathrm{~h})$ & $0.44 \pm 0.08$ & $35.66 \pm 2.77$ & 101.3 \\
GMA grafted LDPE (ATRP for $4 \mathrm{~h})$ & $2.05 \pm 0.08$ & $31.34 \pm 1.86$ & 19.1 \\
GMA grafted LDPE (ATRP for $6 \mathrm{~h})$ & $4.53 \pm 0.15$ & $32.96 \pm 4.63$ & 9.1 \\
\hline LDPENEMAC & $1.53 \pm 0.02$ & $24.46 \pm 1.90$ & 20.0 \\
\hline Specific activity of UK used for immobilization: $80 \mathrm{IU} / \mathrm{\mu g}$
\end{tabular}

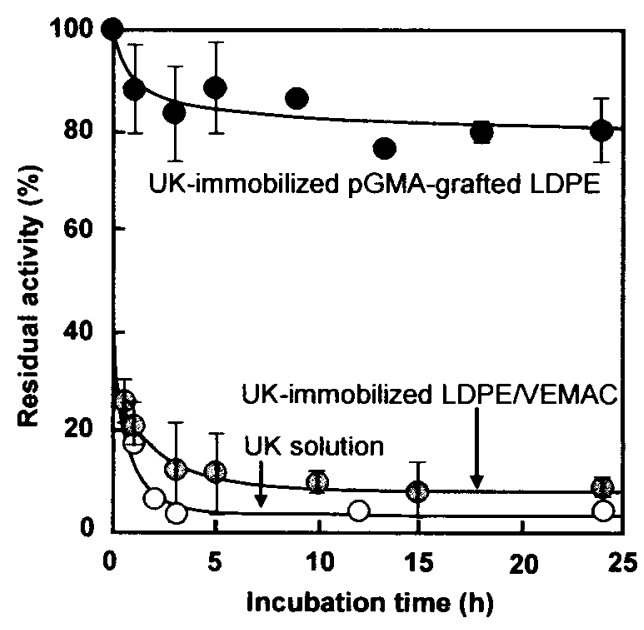

Fig. 3 Progressive changes in enzyme activity of immobilized UK in phosphate buffer solution (pH 7.0) at $37^{\circ} \mathrm{C}$.

sheet at $37{ }^{\circ} \mathrm{C}$ in $10 \mathrm{mM}$ phosphate buffer solution ( $\mathrm{pH} 7.0)$, together with soluble UK $(50 \mathrm{IU} / \mathrm{mL})$ for the comparison purpose. The initial activity of UK immobilized on pGMA-grafted LDPE and LDPE/ VEMAC sheet were $35.56 \pm 2.27 \mathrm{IU} / \mathrm{cm}^{2}$ and $24.46 \pm 1.90 \mathrm{IU} / \mathrm{cm}^{2}$, respectively.

It is seen from Fig. 3 that the UK immobilized on the pGMA-grafted sheet retained about $80 \%$ of its initial activity after $24 \mathrm{~h}$ at $37^{\circ} \mathrm{C}$. On the other hand, the activity of the immobilized UK on LDPE/VEMAC sheet and soluble UK rapidly decreased and reached to less than $10 \%$ in a few hours. These results readily indicate that the stability of UK immobilized on the pGMA-grafted LDPE surface has been considerably improved.

\section{Conclusion}

It can be concluded that the pGMA brushes fabricated under optimum conditions works as the effective interfaces for the covalent immobilization of biomolecules. Further applications using the UK-immobilized polymer sheet thus prepared are now in progress for the development of biocompatible materials.

\section{Acknowledgment}

This work was financially supported in part by a Grant-in-Aid for Science Research from the Ministry of Education, Culture, Sports, Science and Technology of Japan (Grant No. 17590036), which is gratefully acknowledged.

\section{References}

1. M. Kuzuya, T. Yamashiro, S. Kondo, M. Tsuiki, Plasmas and Polymers, 2 (1997) 133.

2. M. Kuzuya, T. Sawa, T. Yamashiro, S. Kondo, O. Takai, J. Photopolym. Sci. Technol, 14 (2001) 87.

3. M. Kuzuya, T. Sawa, M. Mouri, S. Kondo, O. Takai, Sur. Coat. Technol., 169-170 (2003) 587.

4. Y. Sasai, S. Kondo, Y. Yamauchi, M. Kuzuya, $J$. Photopolym. Sci. Technol., 19 (2006) 265.

5. T. Morita, H. Kato, S. Iwanaga, K. Takada, T. Kimura, S. Sakakibara, J. Biochem., 82 (1977) 1495.

6. Y. Yabushita, Biotechnol. Appl. Biochem., 10 (1988) 294. 